\title{
Dynamic Echoventriculography
}

\section{Noninvasive Assessment of Effects of Nitroglycerin, Phenylephrine, Isoproterenol, and Propranolol on the Human Cardiovascular System}

\author{
Yuzo Hirota, M.D., Michihiro Suwa, M.D., \\ Kenjiro Hori, M.D., and Tadasu Takatsu, M.D.
}

\section{Summary}

Effects of nitroglycerin, phenylephrine, isoproterenol, and propranolol on the cardiovascular system were studied sequentially using echocardiography to evaluate a method for a more precise assessment of cardiac function.

Nitroglycerin reduced systolic blood pressere (sBP, 3.9\%, p<0.01), enddiastolic (EDVI, $11.3 \%, \mathrm{p}<0.001$ ), end-systolic volume indices (ESVI, $10.0 \%, \mathrm{p}<0.05)$, stroke index (SI, 13.1\%, $\mathrm{p}<0.005)$, and cardiac index (CI, $7.1 \%, \mathrm{p}<0.05$ ) without changes in diastolic pressure (dBP), mean velocity of circumferential fiber shortening (mean $\mathrm{Vcf}$ ), or ejection fraction (EF). Mid-systolic left ventricular (LV) endocardial stress (STRESS) as an index of afterload decreased by $13.6 \% \quad(\mathrm{p}<0.02)$.

Afterload augmentation by phenylephrine infusion resulted in bradycardia, reductions of CI $(9.6 \%, \mathrm{p}<0.05)$ and mean $\mathrm{Vcf}(11.2 \%, \mathrm{p}<$ $0.001)$ without changes in EF.

Tachycardia, reductions of EDVI $(13.5 \%, \mathrm{p}<0.05)$, ESVI $(46.8 \%$, $\mathrm{p}<0.001)$, and STRESS $(20.3 \%, \mathrm{p}<0.005)$, and augmentations of CI $(29.1 \%, \mathrm{p}<0.001)$, mean Vcf $(62.4 \%, \mathrm{p}<0.001)$, and $\mathrm{EF}(16.2 \%, \mathrm{p}<$ $0.001)$ were induced by isoproterenol administration.

Whereas no significant changes were observed in mean $\mathrm{Vcf}, \mathrm{EF}$, or other parameters of cardiac performance, decrease in LV minute work index $(12.9 \%, \mathrm{p}<0.05)$ with equivalent EDVI suggested minimal depression of LV function with intravenous injection of propranolol.

These hemodynamic changes are in good agreement with the results obtained by animal experiments and invasive investigations. Indices of the 4 major determinants of cardiac performance, preload as enddiastolic dimension or EDVI, afterload as STRESS, contractility as EF or mean Vcf, and heart rate can all be assessed by this noninvasive method. The proposed method of sequential assessment of these parameters, changing preload, afterload, and contractility, i.e., dynamic echoventri-

From the Third Division, Department of Internal Medicine, Osaka Medical College, Takatsuki City, Osaka, Japan.

Address for reprints: Professor T. Takatsu, the Third Division, Department of Internal Medicine, Osaka Medical College, 2-7 Daigaku-cho, Takatsuki City, Osaka 569, Japan.

Received for publication February 6, 1978. 
culography should be a useful tool for the precise evaluation of cardiac function.

Additional Indexing Words :

Preload Afterload Contractility Heart rate Cardiac function Echocardiography

7 HE determinations of hemodynamics and myocardial contractility in1 dices of the patients at rest do not always provide accurate data on cardiac function or reasonably accurate prognosis. ${ }^{1)-7)}$ Therefore, it has been emphasized that determinations should be repeated under conditions of stress, ${ }^{71-11)}$ unloading $^{12), 13)}$ or inotropic stimulations ${ }^{14)}$ to the heart, making use of various techniques. Clinical applications, however, involve additional time, cost, discomfort, and risks to the patients which often incurred with cardiac catheterization and angiography.

There is increasing evidence that the noninvasive assessment of cardiac function as determined by echocardiography relates well with data obtained by invasive methods. ${ }^{15)-24)}$ Although there are still inherent technical problems, ${ }^{25)-27)}$ feasibility of this technique for the determination of left ventricular (LV) function has been well accepted with certain limitations. ${ }^{26,27)}$

The present work was an attempt to evaluate echocardiographically obtained hemodynamics and LV contractile state at rest, and after changing preload, afterload, and inotropic state by pharmacological interventions, in a sequential fashion. The effects of short acting drugs such as nitroglycerin (TNG), phenylephrine (PHEN), isoproterenol (ISOP), and propranolol (PROP) were utilized in normal volunteers.

\section{METHODS}

Six males and 6 females, aged 16 to 37 years, were the subjects of this investigation. A precise history was taken, and physical examination, chest X-ray, electrocardiogram, and diagnostic echocardiogram were reviewed in each case to rule out the possible existence of subclinical heart disease. Informed consents were obtained from them.

Individuals in fasting state and without premedications rested quietly for 15 to $20 \mathrm{~min}$ before control echocardiograms were recorded. Four to $8 \mathrm{~min}$ after the sublingual administration of TNG $(0.3 \mathrm{mg})$, echocardiograms were obtained. PHEN and ISOP echocardiograms were recorded 4 to $8 \mathrm{~min}$ after the initiation of a drip infusion of $50 \mu \mathrm{g} / \mathrm{min}$ and 0.75 to $1.0 \mu \mathrm{g} / \mathrm{min}$, resepctively. Four $\mathrm{mg}$ of PROP was injected intravenously over $1 \mathrm{~min}$ and echocardiograms were repeated 4 to $8 \mathrm{~min}$ after the injection. Blood pressure was measured with a cuff manometer just after each of these recordings. The procedure was performed in this sequence, and the effects of the previous medication were assumed to have disappeared when 
heart rate, blood pressure, and LV size and shape returned to control conditions. At least $20 \mathrm{~min}$ after the termination of the previous recording was required to initiate the next drug administration. Two or 3 recordings were obtained on each occasion to ascertain that the same LV segment was recorded. Six to 8 heart cycles were recorded and the pericardial echo was identified at the end of each recording using a damping procedure, while the volunteers held their breath near the end-expiration.

Echocardiograms were recorded with ALOKA SSD 90, having a repetition rate of 1000 pulse/sec and utilizing a $2.25 \mathrm{MHz}, 1 \mathrm{~cm}$ in diameter and non-focused transducer. The ultrasonic beam was introduced from the 3rd or 4th left intercostal space to the left ventricle, where the endocardial echoes of the interventricular septum and posterior wall were clearly identified, and the tip of both leaflets of the mitral valve were recorded between them, as described by Feigenbaum. ${ }^{26}$ ) Photographic recording was obtained at the paper speed of $100 \mathrm{~mm} / \mathrm{sec}$ with simultaneous recordings of electrocardiogram and phonocardiogram. Five consecutive beats were averaged for the determination of the parameters. All recordings and measurements were performed by a single investigator (M.S.) to avoid personal variations of the technique.

End-diastolic dimension ( $\mathrm{Dd}, \mathrm{cm}$ ) was measured at the end of the isovolumic contraction, and end-systolic dimension $(\mathrm{Ds}, \mathrm{cm})$ at the point of the onset of the 2nd heart sound. Ejection time (ET, sec) was defined as the time interval between

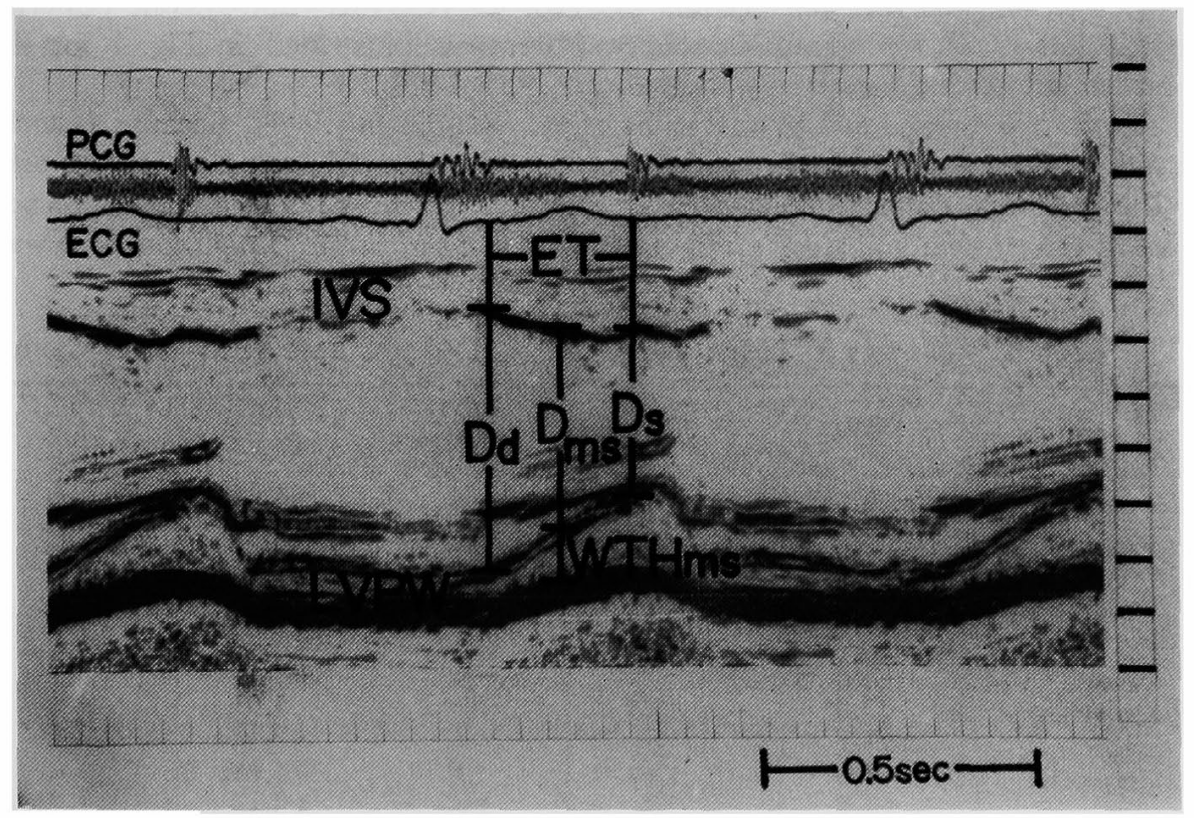

Fig. 1. A representative echocardiogram with identification of the points of measurements. PCG: phonocardiogram, ECG: electrocardiogram, IVS: interventricular septum, LVPW: left ventricular posterior wall, Dd: enddiastolic dimension, Ds: end-systolic dimension, ET: ejection time, Dms: dimension at the mid-systole, WTHms: posterior wall thickness at the midsytole. 
Dd and Ds to calculate mean velocity of circumferential fiber shortening (mean $\mathrm{Vcf}, \operatorname{circ} / \mathrm{sec}$ ), which was obtained by the formula: (Dd-Ds)/ET $\times \mathrm{Dd}$. LV enddiastolic and end-systolic volume indices (EDVI and ESVI, respectively, $\mathrm{ml} / \mathbf{M}^{2}$ ) were calculated by cubing $\mathrm{Dd}$ and $\mathrm{DS}_{\mathrm{s}}$, and corrected by body surface area. ${ }^{16,20)}$ Stroke index (SI, $\mathrm{ml} / \mathrm{M}^{2}$ ) was obtained by subtracting ESVI from EDVI, and cardiac index $\left(\mathrm{CI}, \mathrm{L} / \mathrm{min} / \mathrm{M}^{2}\right)$ was calculated by $\mathrm{SI}$ times heart rate. Ejection fraction (EF, \%) was obtained by the formula: $\left(\mathrm{Dd}^{3}-\mathrm{Ds}^{3}\right) / \mathrm{Dd}^{3}$.

Systemic vascular resistance (SVR, dynes $\cdot \mathrm{sec} \cdot \mathrm{cm}^{-5}$ ), LV minute work index (LVMWI, $\mathrm{Kg} \cdot \mathrm{M} / \mathrm{min} / \mathrm{M}^{2}$ ) and mid-systolic LV endocardial stress (STRESS, $\mathrm{Gm} / \mathrm{cm}^{2}$ ) were estimated to assess the directional changes of SVR, LV performance and afterload with the pharmacological interventions. The following formulae were employed: $\mathrm{SVR}=\left(\frac{\mathrm{sBP}+2 \mathrm{dBP}}{3}\right) \times 80 / \mathrm{CO}$, where $\mathrm{sBP}$ was systolic blood pressure, $\mathrm{dBP}$ was diastolic blood pressure and $\mathrm{CO}$ was cardiac output obtained echocardiographically; LVMWI $=13.6 \times \mathrm{sBP} \times \mathrm{CI} / 1000$, where $\mathrm{sBP}$ was assumed to be mean LV systolic pressure and $L V$ end-diastolic pressure was neglected; STRESS $=\frac{7}{16} \times \frac{\mathrm{sBP} \times \mathrm{Dms}}{\mathrm{WTHms}}$, after the modification of the formula for the thickwalled ellipsoid model, ${ }^{28)}$ i.e. stress $=\frac{\mathrm{Pb}}{\mathrm{h}} \times\left(1-\frac{\mathrm{b}^{2}}{2 \mathrm{a}^{2}}\right)$, where $\mathrm{p}=$ pressure $=\mathrm{sBP}, \mathrm{b}=$ short radius, which was assumed to be one half of echocardiographically measured dimension at the mid-systole $(b=$ Dms/2), $a=$ long radius, which was assumed to be twice as long as the short radius $(a=2 b), h=$ WTHms = mid-systolic posterior wall thickness. A representative echocardiogram is illustrated in Fig. 1 for the identification of the measured points.

Preload is defined as LV wall stress at the end-diastole, ${ }^{11,29)}$ Because of technical difficulties involved in determining stress, end-diastolic pressure has been used for the index. ${ }^{11}$ Echocardiographically obtained Dd or EDVI can be employed as an alternative index, since stress is derived from pressure, dimension, and wall

Tabl I. Changes in Heart Rate, Blood Pressure, Left Ventricular Cavity,

\begin{tabular}{c|c|c|c|c|c}
\hline & HR & $\begin{array}{c}\mathrm{sBP} \\
(\mathrm{mmHg})\end{array}$ & $\begin{array}{c}\mathrm{dBP} \\
(\mathrm{mmHg})\end{array}$ & $\begin{array}{c}\mathrm{Dd} \\
(\mathrm{cm})\end{array}$ & $\begin{array}{c}\mathrm{Ds} \\
(\mathrm{cm})\end{array}$ \\
\hline Control & 65.6 & 113 & 69 & 4.93 & 3.24 \\
& \pm 1.9 & \pm 5 & \pm 3 & \pm 0.11 & \pm 0.10 \\
range min. & 59.7 & 94 & 60 & 4.4 & 2.5 \\
max. & 79.0 & 160 & 90 & 5.5 & 3.7 \\
Nitroglycerin & $68.8 *$ & $107 \dagger$ & 69 & $4.73^{*}$ & $3.13 *$ \\
Phenylephrine & \pm 2.2 & \pm 4 & \pm 2 & \pm 0.11 & $\pm 0.10^{*}$ \\
& $55.9^{*}$ & $133^{*}$ & $88^{*}$ & 5.03 & 3.38 \\
Isoproterenol & \pm 1.2 & \pm 5 & \pm 2 & \pm 0.11 & \pm 0.12 \\
& $84.6^{*}$ & $126 \S$ & 535 & $4.68 *$ & $2.63^{*}$ \\
Propranolol & \pm 3.2 & \pm 5 & \pm 6 & \pm 0.12 & \pm 0.09 \\
& $59.1 \dagger$ & 110 & 70 & 4.90 & 323 \\
& \pm 1.3 & \pm 5 & \pm 3 & \pm 0.11 & \pm 0.13
\end{tabular}

No. $=12, \quad \mathrm{Mn} \pm \mathrm{SEM}, \quad \mathrm{HR}=$ heart rate, $\mathrm{sBP}=$ systolic blood pressure, $\mathrm{dBP}=$ diastolic blood pressure, Dd=end-diastolic dimension, Ds=end-systolic dimension, EDVI=end-diastolic volume index, $\mathrm{ESVI}=$ end-systolic volume index, $\mathrm{SI}=$ stroke index, $\mathrm{CI}=$ cardiac index, $\mathrm{EF}=$ ejection 
thickness (Laplace). Afterload is also defined as stress to the ventricle during systole. ${ }^{29)}$ Mid-systolic LV endocardial stress was used here as a noninvasive index of afterload. This index was found to be an accurate index of afterload comparing to the peak and mean systolic LV stress measured by echocardiography and a

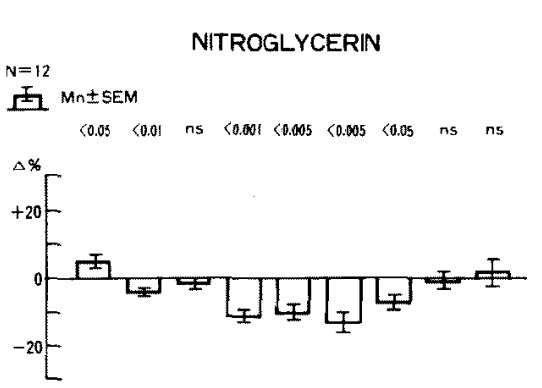

PHENYLEPHRINE

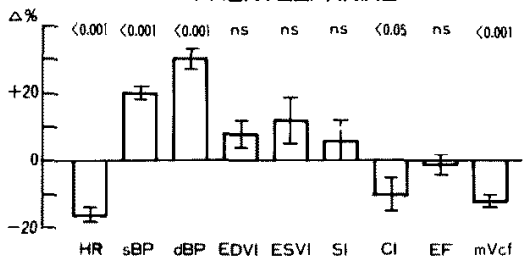

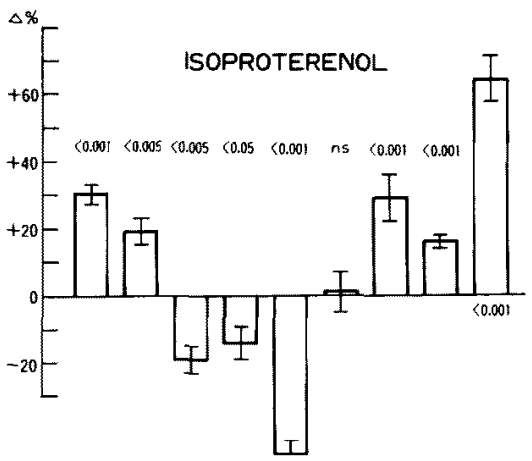

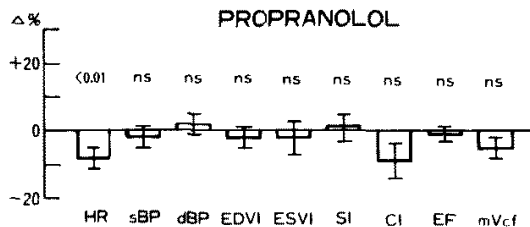

Fig. 2. Echocardiographic observations of hemodynamic changes with nitroglycerin, phenylephrine, isoproterenol, and propranolol. The percentile changes $(\Delta \%)$ from the control state are shown. The " $p$ " values ncxt to the bars indicate comparisons with the control state prior to the interventions. ns: non-significant $(\mathrm{p}>0.05)$, $\mathrm{HR}$ : heart rate, $\mathrm{sBP}$ : systolic blood pressure, dBP: diastolic blood pressure, EDVI: left ventricular end-diastolic volume index, ESVI: left ventricular end-systolic volume index, SI: stroke index, CI: cardiac index, EF : ejection fraction, mVcf: mean velocity of circumferential fiber shortening.

Cardiac Output and Contractility Indices with Pharmacological Interventions

\begin{tabular}{|c|c|c|c|c|c}
\hline $\begin{array}{c}\text { EDVI } \\
\left(\mathrm{ml} / \mathrm{M}^{2}\right)\end{array}$ & $\begin{array}{c}\mathrm{ESVI} \\
\left(\mathrm{ml} / \mathrm{M}^{2}\right)\end{array}$ & $\begin{array}{c}\mathrm{SI} \\
\left(\mathrm{ml} / \mathrm{M}^{2}\right)\end{array}$ & $\begin{array}{c}\mathrm{CI} \\
\left(\mathrm{L} / \mathrm{min} / \mathrm{M}^{2}\right)\end{array}$ & $\begin{array}{c}\mathrm{EF} \\
(\%)\end{array}$ & $\begin{array}{c}\text { mean Vcf } \\
(\mathrm{circ} / \mathrm{sec})\end{array}$ \\
\hline 76 & 22 & 54 & 3.52 & 71 & 1.19 \\
\pm 4 & \pm 2 & \pm 3 & \pm 0.17 & \pm 2 & \pm 0.05 \\
60 & 10 & 40 & 2.69 & 64 & 0.97 \\
105 & 30 & 70 & 4.61 & 85 & 1.55 \\
$67^{*}$ & $20 *$ & 485 & $3.23 *$ & 71 & 1.21 \\
\pm 4 & \pm 1 & \pm 3 & \pm 0.15 & \pm 2 & \pm 0.04 \\
81 & 25 & 56 & $3.13 *$ & 70 & $1.04^{*}$ \\
\pm 4 & \pm 2 & \pm 3 & \pm 0.14 & \pm 2 & \pm 0.04 \\
$65 *$ & $12 *$ & 54 & $4.51^{*}$ & $81^{*}$ & $1.94^{*}$ \\
\pm 4 & \pm 2 & \pm 3 & \pm 0.17 & \pm 1 & \pm 0.10 \\
76 & 22 & 54 & 3.18 & 71 & 1.13 \\
\pm 4 & \pm 2 & \pm 3 & \pm 0.21 & \pm 2 & \pm 0.06 \\
\hline
\end{tabular}

fraction, mean $V c f=$ mean velocity of circumferential fiber shortening, $\min .=$ minimal value, and max. $=$ maximal value of control state. Statistical analysis was made comparing parameters at rest, control state with those after interventions: ${ }^{*}=p<0.001, s=p<0.005, t=p<0.01, * *=p<0.05$ 
catheter tip manometer. ${ }^{30)}$ EF and mean Vcf were measured as indices of contractility.

Data were expressed as mean \pm standard error of the mean $(\mathrm{Mn} \pm \mathrm{SEM})$. Paired t-test was employed for the statistical analysis.

\section{Results}

Results are summarized in Tables I and II, and illustrated as percentile changes from the control in Figs. 2 and 3.

Hemodynamic parameters and contractility indices at rest measured by echocardiography were in the relatively narrow range of normal values reported in the literature. ${ }^{\mathbf{1 6}), 21,-24), 31)-36 \text { ) }}$

After the administration of TNG, the heart rate increased slightly with minimal reduction of sBP. Both Dd and Ds decreased significantly, resulting in reductions of $\operatorname{EDVI}(11.3 \%, \mathrm{p}<0.001)$ and $\operatorname{ESVI}(10.0 \%, \mathrm{p}<0.05)$. SI and CI fell slightly, but significantly. STRFSS decreased by $13.6 \%(\mathrm{p}<$ 0.02). This dose of TNG had no cffects on dBP, EF, mean Vcf, or SVR. Thus nitroglycerin given in a small dose sublingually reduces preload and has no effects on the arteriolar bed. As the normal human ventricle is on the ascending limb of Starling's curve, ${ }^{12}$ ) reduction of preload produces a decrease in CI, LVMWI, and afterload to the heart (Figs. 3, 4).

Elevation of afterload with PHEN, as demonstrated by a increase in sBP, $\mathrm{dBP}, \mathrm{SVR}$, and STRESS (all $\mathrm{p}<0.001$ ) resulted in bradycardia, reductions of CI $(9.6 \%, \mathrm{p}<0.05)$ and mean Vcf $(12.2 \%, \mathrm{p}<0.001)$. EDVI, ESVI, and

Table II. Noninvasive Estimations of Systemic Vascular Resistance, Afterload, and Left Ventricular Work

\begin{tabular}{c|c|c|c}
\hline & $\begin{array}{c}\text { SVR } \\
\left(\text { dynes. sec } \cdot \mathrm{cm}^{-5}\right)\end{array}$ & $\begin{array}{c}\text { STRESS } \\
\left(\mathrm{Gm} / \mathrm{cm}^{2}\right)\end{array}$ & $\begin{array}{c}\text { LVMWI } \\
\left(\mathrm{Kg} \cdot \mathrm{M} / \mathrm{min} / \mathrm{M}^{2}\right)\end{array}$ \\
\hline Control & 1232 & 260 & 5.45 \\
range min. & \pm 79 & \pm 17 & \pm 0.43 \\
& 874 & 192 & 3.73 \\
Nitroglycerin & 1550 & 410 & 9.19 \\
& 1279 & $222 \dagger$ & 4.725 \\
Phenylephrine & \pm 61 & \pm 9 & \pm 0.27 \\
& $1739 *$ & $334 *$ & 5.66 \\
Isoproterenol & \pm 84 & \pm 24 & \pm 0.42 \\
& 9375 & 2045 & $7.73^{*}$ \\
Propranolol & \pm 88 & \pm 16 & \pm 0.58 \\
& 1363 & 242 & $4.77 *$ \\
& \pm 71 & \pm 17 & \pm 0.40
\end{tabular}

No.=12, Mn \pm SEM, SVR=systemic vascular resistance, STRESS=mid-systolic left ventricular wall stress, $L V M W I=$ left ventricular minute work index, $\min ,=\operatorname{minimal}$ value, and $\max =$ maximal value of the control state. $*=p<0.001, \delta=p<0.005, t=p<0.02, *=p<0.05$ 
SYSTEMIC VASCULAR RESISTANCE
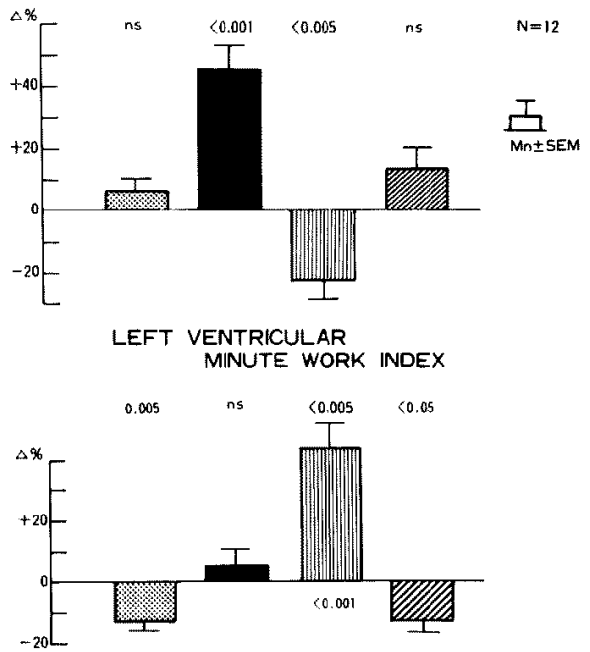

MID-SYSTOLIC LEFT

VENTRICULAR STRESS

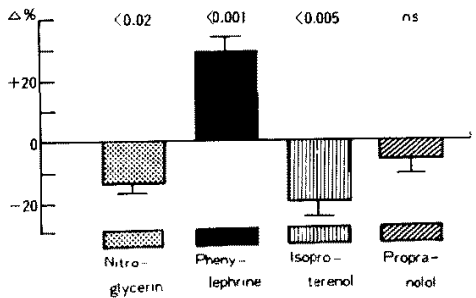

Fig. 3. The percentile changes $(\Delta \%)$ of systemic vascular resistance, left ventricular minute work index and mid-systolic left ventricular endocardial stress from the control state, estimated by echocardiography and cuff measured blood pressure. The " $p$ " values next to the bars indicate comparisons with the control state prior to the interventions.

LVMWI showed a trend toward increments, but they were not statistically significant. No changes were observed in EF. It has been reported that the ejection phase indices of contractility are sensitive to afterload changes. ${ }^{4), 37), 38 \text {, }}$ However, reduction of mean Vcf without significant change in EF may be due to bradycardia, since mean Vcf is also scnsitive to the changes in heart rate ${ }^{37}$ )

Tachycardia, elevation of $\mathrm{sBP}$, and reduction in $\mathrm{dBP}$ as well as $\mathrm{LV}$ cavity were evident after a minimal dose of ISOP infusion. An increase in CI, EF, and mean Vef was observed. Arteriolar dilatation and afterload reduction were seen by a decrease in SVR $(23.2 \%, \mathrm{p}<0.005)$ and STRESS $(20.8 \%, \mathrm{p}<0.005)$. These changes clearly demonstrated that ISOP was a potent inotropic agent (Figs. 4, 5). 


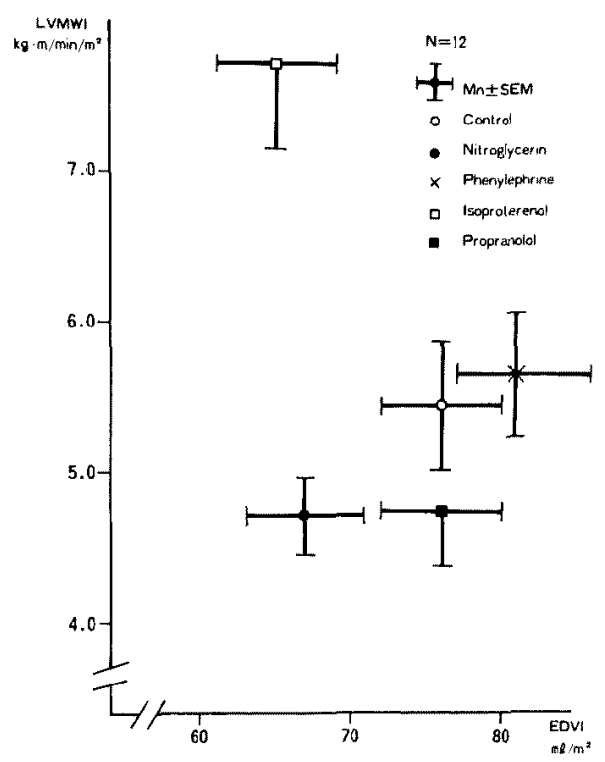

Fig. 4. The relationship between left ventricular minute work index (LVMWI, as an index of ventricular performance) and left ventricular enddiastolic volume index (EDVI, as an index of preload). While ventricular functions are on one line of Starling's curve at rest, and after nitroglycerin and phenylephrine administration, the function curve shifted upward with isoproterenol and downward with propranolol. The observations indicate that while nitroglycerin and phenylephrine have no significant inotropic effects, isoproterenol is a potent inotropic agent and propranolol possesses mild negative inotropic effect.

Significant changes in hemodynamic parameters and contractility indices were not observed with PROP, except for mild bradycardia. Slight reduction of LVMWI $(12.9 \%, \mathrm{p}<0.05)$ with the equivalent level of preload comparing to the control state, however, indicates a minimal depression of $\mathrm{LV}$ function (Fig. 4).

\section{Discussion}

TNG, PHEN, ISOP, and PROP are all compounds used universally in daily practice, and the effects of these drugs on the cardiovascular system have been investigated in experimental animal models and clinical studies.

A small dose of TNG mainly produces dilatation of capacitant vessels with minimal arteriolar dilatation. ${ }^{39}$ ) Reduction of preload without changes in contractility produces a decrease in cardiac output, since ventricular function is on the ascending limb of Starling's curve in normal subjects. ${ }^{12), 39)}$ Our observation is in agreement with those invasive investigations. As TNG 


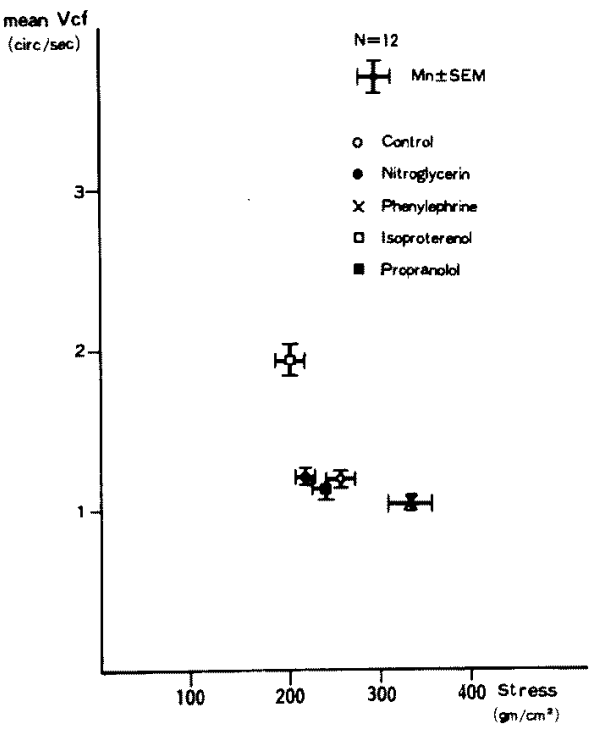

Fig. 5. The relationship between mean velocity of circumferential fiber shortening (mean Vcf) and mid-systolic left ventricular endocardial stress (STRESS, as an index of afterload). Afterload augmentation with phenylephrine resulted in reduction of mean Vcf, which was explained as the result of afterload mismatch without significant preload reserve. Significant increase in mean Vcf was not observed with afterload reduction by nitroglycerin, which was due to significant reduction of preload (negative preload reserve). Increment of mean $\mathrm{Vcf}$ was out of proportion to the reduction of afterload with isoproterenol, which indicated positive inotropic effect of this agent.

reduces $\mathrm{LV}$ volume and $\mathrm{SBP}$, it can safely be assumed that it also reduces afterload. Significant reduction of STRESS was demonstrated herein. Although DeMaria et al $^{40)}$ reported a significant reduction of mean Vcf with this agent, a $31 \%$ increase in mean Vcf was observed by Redwood and coworkers. ${ }^{41)}$ We did not, however, note any significant changes. This is probably the counterbalanced effects of reductions of afterload and preload, considering the concept of afterload mismatch and preload reserve. ${ }^{38)}$

Since PHEN is a potent alpha-adrenergic stimulator, arteriolar constriction is followed by an increase in afterload. ${ }^{42}$ Bradycardia, and decrease in cardiac output and mean Vcf are associated with administration of this compound. ${ }^{42,43)}$ Such effects can be well demonstrated by this noninvasive method. A question may be raised whether a significant reduction of mean $\mathrm{Vcf}$ without changes in EF is due to the effects of bradycardia and not due to the elevation of afterload, since mean $\mathrm{Vcf}$ is sensitive to heart rate changes. ${ }^{37}$ ) Although a clear answer can not be derived from this investigation, we think the reduction in mean Vcf is due to afterload mismatch and mean Vcf is 
more sensitive to the change in afterload than EF, ${ }^{37}$ ) since bradycardia induced by PROP was not associated with changes in it. Whereas significant increase in LV cavity was reported with a large dose of PHEN, ${ }^{43}$ ) we noted a trend toward increment. As the enlargement of the cavity with acute elevation of arterial pressure is minimal, ${ }^{44}$ ) the detection of the cavity changes is probably beyond the sensitivity of this method, if afterload is augmented mildly as was seen in this study.

Dilatation of resistance vessels, strong positive inotropic and chronotropic effects of ISOP were clearly demonstrated with infusion of a minimal dose.

Although there is almost unanimous agreement that PROP is a cardiac depressant, there is conflicting evidence as to whether this drug depresses the function of the normal human ventricle at rest. ${ }^{11}$ We observed nonsignificant changes in the cavity size, CI, EF, and mean Vcf, and yet the observation suggests minimal depression of LV function with PROP (Fig. 4).

\section{Clinical Application and Limitation of This Method}

Preload, afterload, contractility, and the heart rate are the major determinants of cardiac function, and cardiac performance consists of a complex integration of these factors. Therefore, it is preferable to determine each one for a precise evaluation of the function. ${ }^{29}$ ) Preload is defined as LV wall stress at end-diastole. ${ }^{1,29), 46), 47)}$ Because of technical difficulties involved in determining stress, end-diastolic pressure has been used for the index of preload. ${ }^{1)}$ Echocardiographically obtained Dd or EDVI can be employed as an alternative index, since stress is derived from pressure, dimension, and wall thinkness (Laplace). Assessment of afterload is more difficult, even with an invasive method. Peak systolic stress by Hood et al, ${ }^{33)}$ wall stress at aortic valve opening by Ratshin and coworkers, ${ }^{46)}$ and arterial impedance by Milnor ${ }^{47)}$ have been proposed as indices of afterload. These measurements, howcver, require an invasive technique and sophisticated calculations. Midsystolic LV endocardial stress (STRESS); proposed here, was found to be an acurrate noninvasive index of afterload. ${ }^{30}$ EF and mean $\mathrm{Vcf}$ are widely accepted as indices of contractility. ${ }^{29}$ )

Determinations of preload as Dd or EDVI, afterload as STRESS, contractility as EF or mean Vcf and heart rate are possible by echocardiography and blood pressure measured by a cuff manometer. Assessment of these parameters with changing these factors by sequential pharmacological interventions carried out herein as dynamic echoventriculography may be a suitable tool for a more precise assessment of cardiac function.

Fourteen volunteers were investigated initially and 2 cases were excluded from the analysis, because of poor quality of the echocardiogram when ISOP 
was infused. Several other volunteers could not be entered into the investigation, because reasonable $L V$ recording was not obtained at the time of diagnostic echocardiographic examination.

It is well known that in cases with $L V$ wall dyskinesis and paradoxical septal movement, echocardiographically measured LV volumes and mean Vcf are not reliable, ${ }^{26), 271,48}$ and so this method can not be applied in such patients. LV volume was estimated by cubing the dimension in this investigation, assuming the long axis of LV cavity is twice as long as the short axis. The cavity becomes near spherical in patients with enlarged heart, however, and other formulae than cubed dimension are preferable for the determination of LV volume when this method is employed clinically. ${ }^{26), 27)}$

Although there are theoretical and technical problems in the assessment of LV function by means of echocardiography, ${ }^{25,-27), 48)}$ informations by this noninvasive method should not be minimized. ${ }^{26,27)}$ Dynamic echoventriculography may be an important diagnostic tool.

\section{ACKNOWLEDGEMENTS}

Thanks are due to Prof. C. Kawai and M. Ohara of Kyoto University for pertinent advice and assistance with the manuscript.

\section{REFERENCES}

1. Braunwald E, Ross J Jr: The ventricular end-diastolic pressure. Appraisal of its value in the recognition of ventricular failure in man. Am J Med 34:147, 1963

2. Mason DT: Usefulness and limitations of the rate of rise of intraventricular pressure (dp/dt) in evaluation of myocardial contractility in man. Am J Cardiol 23: 516, 1969

3. Hugenholtz PG, Ellison RC, Urschel CW, Mirsky I, Sonnenblick EH: Myocardial forcevelocity relationships in clinical heart disease. Circulation 41: 191, 1970

4. Ross J Jr, Peterson KL: On the assessment of cardiac inotropic state. Circulation 47: 435, 1973

5. Peterson KL, Skloven D, Ludbrook PL, Uther JB, Ross J Jr: Comparison of isovolumic and ejection phase indices of myocardial performance in man. Circulation 49: 1088, 1974

6. Kreulen TH, Bove AA, McDonough MT, Sands MJ, Spann JF: The evaluation of left ventricular function in man. A comparison of methods. Circulation 51:677, 1975

7. Krayenbuehl HP, Rutishauser W, Wirz P, Amende I, Mehmel H: High-fidelity left ventricular pressure measurements for the assessment of cardiac contractility in man. Am J Cardiol 31: 415, 1973

8. Ross J Jr, Gault JH, Mason DT, Linhart JW, Braunwald E: Left ventricular performance during muscular exercise in patients with and without cardiac dysfunction. Circulation 34: 597,1966

9. Kivowitz G, Parmley WW, Donoso R, Marcus H, Ganz W, Swan HJC: Effects of isometric exercise on cardiac performance. The grip test. Circulation 44: 994, 1971

10. Khaja F, Parker JO, Ledwich RJ, West RO, Armstrong PW: Assessment of ventricular function in coronary artery disease by means of atrial pacing and exercise. Am $J$ Cardiol 26: 107,1970 
11. Cohn PF, Horn HR, Teichholz LE, Kreulen TH, Herman MV, Gorlin R: Effects of angiographic contrast medium on left ventricular function in coronary artery disease. Comparison with static and dynamic exercise. Am J Cardiol 32: 21, 1973

12. Ross J Jr, Braunwald E: Studies on Starling's law of the heart. IX. The effects of impeding venous return on performance of the normal and failing human left ventricle. Circulation 30: 719,1964

13. Reddy SP, Curtiss EI, O'Toole JD, Matthews RG, Salerni R, Leon DF, Shaver JA: Reversibility of left ventricular asynergy by nitroglycerin in coronary artery disease. Am Heart J 90: 479,1975

14. Cohn PF, Gorlin R, Herman MV, Sonnenblick EH, Horn HR, Cohn LH, Collins JJ Jr: Relation between contractile reserve and prognosis in patients with coronary artery disease and a depressed ejection fraction. Circulation 51: 414, 1975

15. Popp RL, Harrison DC: Ultrasonic cardiac echography for determining stroke volume and valvular regurgitation. Circulation $41: 493,1970$

16. Pombo JF, Troy BL, Russell RO Jr: Left ventricular volumes and ejection fraction by echocardiography, Circulation 43: 480, 1971

17. Pombo JF, Russell RO Jr, Rackley CE, Foster GL: Comparison of stroke volume and cardiac output determination by ultrasound and dye dilution in acute myocardial infarction. Am J Cardiol 27: 630, 1971

18. Fortuin NJ, Hood WP Jr, Sherman ME, Creige E: Determination of left ventricular volumes by ultrasound. Circulation 44: 575, 1971

19. Gibson DG: Estimation of left ventricular size by echocardiography, Brit Heart $\mathbf{J} 35$ : 128,1973

20. Feigenbaum H, Popp RL, Wolfe SB, Troy BL, Pombo JF, Haine CL, Dodge HT: Ultrasound measurements of the left ventricle. A correlative study with angiography. Arch Intern Med 129: 461, 1972

21. Gooper RH, O'Rourke RA, Karliner JS, Peterson KL, Lcopold GR: Comparison of ultrasound and cineangiographic measurements of the mean rate of circumferential fiber shortening in man. Girculation 46: 914, 1972

22. Murray JA, Johnston W, Reid JM: Echocardiographic determination of left ventricular dimensions, volumes and performance. Am J Cardiol 30: 252, 1972

23. Belenkie I, Nutter DO, Clark DW, McCraw DB, Raizner AE: Assessment of left ventricular dimensions and function by echocardiography. Am J Cardiol 31 : 755, 1973

24. ten-Cate FJ, Kloster FE, van Dorp WG, Meester GT, Roelandt J: Dimensions and volumes of left atrium and ventricle determined by single beam echocardiography. Brit Heart J 36: 737,1974

25. Evans DH, McDicken WN, Robertson DAR: The accuracy of cardiac function indices derived from ultrasonic time-position scan. Cardiovasc Res 10: 65, 1975

26. Feigenbaum H: Echocardiographic examination of the left ventricle. Circulation 51: 1, 1975

27. Joyner CR: Echocardiography. Am Heart J 90:413, 1975

28. Mirsky I: Review of various theories for the evaluation of left ventricular wall stress. in Cardiac Mechanics. Physiological, Clinical and Mathematical Considerations (ed by Mirsky I, Ghista DN, Sandler H). John Wiley \& Sons Inc., New York, p 390, 1974

29. Braunwald E, Ross J Jr, Sonneriblick EHI: Methods for assessing cardiac contractility. in Mechanisms of the Contraction of the Normal and Failing Heart. 2nd ed, Little Brown \& Company, Boston, pp 130-165, 1976

30. Hirota Y, Suwa M, Takatsu T: Mid-systolic left ventricular endocardial stress as a noninvasive index of afterload. J Cardiography 8:99, 1978

31. Grossman W: Normal values. In: Cardiac Catheterization and Angiography (ed by Grossman W). Lea \& Febiger, Philadelphia, p 329, 1974

32. Kennedy JW, Baxley WA, Figley MM, Dodge HT, Blackmon JR: Quantitative angiography. 
I. The normal left ventricle in man. Circulation 34:272, 1966

33. Hood WP Jr, Rackley CE, Rolett EL: Wall stress in the normal and hypertrophied human left ventricle. Am J Cardiol 22: 550, 1968

34. Paraskos JA, Grossman W, Saltz S, Dalen JE, Dexter L: A noninvasive technique for the determination of velocity of circumferential fiber shortening in man. Circulat Res 29:610, 1971

35. McDonald IG, Feigenbaum $\mathrm{H}$, Chang $\mathrm{S}$ : Analysis of left ventricular wall motion by reflected ultrasound. Application to assessment of myocardial function. Circulation 46: 14, 1972

36. Quinones MA, Gaasch WH, Alexander JK: Echocardiographic assessment of the left ventricular function, with special reference to normalized velocities. Circulation 50:42, 1974

37. Quinones MA, Gaasch WH, Alexander JK: Influence of acute changes in preload, afterload, contractile state and heart rate on ejection and isovolumic indices of myocardial contractility in man. Girculation 53: 293, 1976

38. Ross J Jr: Afterload mismatch and preload reverve. A conceptual framework for the analysis of ventricular function. Prog Cardiovasc Dis 18: 255, 1976

39. Miller RR, Williams DO, DeMaria AM, Amsterdam EA, Mason DT: Ventricular afterloadreducing agents in congestive heart failure therapy. in Congestive Heart Failure. Mechanisms Evaluation and Treatment (ed by Mason DT). Yorke Med Books, New York, pp 343-364, 1976

40. DeMaria AN, Vismara LA, Auditore K, Amsterdam EA, Zelis R, Mason DT: Effects of nitroglycerin of left ventricular cavity size and cardiac performance determined by ultrasound in man. Am J Med 57: 754, 1974

41. Redwood DR, Henry WL, Epstein SE: Evaluation of the ability of echocardiography to measure acute alterations in left ventricular volume. Circulation 50: 901, 1974

42. Eckstein JW, Abboud FM: Circulatory effects of sympathetic amines. Am Heart J 63: 119,1962

43. Hirshleifer J, Crawford M, O'Rourke RA, Karliner JS: Influence of acute alterations in heart rate and systemic arterial pressure on echocardiographic measures of left ventricular performance in normal human subjects. Circulation 52: 835, 1975

44. Sasayama S, Ross J Jr, Franklin D, Bloor CM, Bishop S, Dilley RB: Adaptation of the left ventricle to chronic pressure overload. Circulat Res 38: 172, 1976

45. Linden RJ, Harry JD: The evaluation of drugs affecting the heart, in Progress in Cardiology 3 (ed by Yu PN, Goodwin JF), Lea \& Febiger, Philadelphia, p 227, 1974

46. Ratshin RA, Rackley CE, Russell RO Jr: Determination of left ventricular preload and afterload by quantitative echocardiography. Circulat Res 34: 711, 1974

47. Milnor WR: Arterial impedance as ventricular afterload. Circulat Res 36: 565,1975

48. Kotler MN, Segal BL, Mintz G, Parry WR: Pitfalls and limitations of M-mode echocardiography. Am Heart J $94: 227,1977$ 